\title{
The Impact of Organizational Structure and Leadership Styles on Innovation
}

\author{
Kenneth Chukwujioke Agbim \\ Business Administration Department, College of Management Sciences, University of Agricultural, Makurdi, \\ Nigeria
}

\begin{abstract}
Generally, organizations build up their competitive advantage by enlarging and enhancing their idea repository, mainly through formal organisationl structure. However, this study was designed to bring to the fore the relevance of the informal social relations (like leadership and relationship styles) in the innovation process. To achieve this objective, the study investigated the link among organic and mechanistic structures, leadership and relationship styles, and the innovation process through the lens of the knowledge creation theory. Data was collected by means of questionnaires and analysed using regression anaslysis. It was found that: the organic structure impacts idea generation; mechanistic structure impacts idea implementation; transformational leadership impacts idea generation; transactional leadership impacts idea implementation; relationship styles moderates the impact of transformational leadership on idea generation; and relationship styles moderates the impact of transactional leadership on idea implementation. This the refore connotes that an organization could be ambidextrous at the same time and within the same department. A manager that is aspiring to develop innovative employees and a competitive organization in a turbulent environment is thus advised to employ both structures and leadership styles with a good relationship atmosphere among employees within the organization.
\end{abstract}

Keywords: Innovation, Leadership styles, Organizational structure, Relationship styles, Turbulent environment

\section{Introduction}

Organizations today are immersed in a competitive and constantly changing environment (Karami, 2008; Oghojafor et al., 2011). These changes basically include: changes in products/services; technology and markets. For instance, several products are being reinvented while the advancement in Information, Communication and Technology (ICT) is continuously turning-around the way and manner services and/or products are being delivered or produced. Furthermore, increase in corruption with the attendant changes in the status of those involved; incessant occurrence of natural disasters with their attendant death tolls; increase in fertility rate with its incidence of high population rate among other issues are gradually occasioning the rapid changes in markets all over the world. Above all, mention must be made of the consequential effects of the global economic meltdown in the environment of business (Akpotu, 2008; Oki, 2009). This, of course, implies that the aforementioned issues and many more have increased the turbulence in the environment and have further precipitated factors that tend to influence the decisions and operations of organizations. To adapt, change and by extension generate more profit, organizations need to continuously reinvent themselves. One of the ways through which organizations do this is by being innovative. Innovation is a critical force in the improvement of organizational performance and in enhancing economic growth and development. More so, organizations must be innovative to survive and flourish in the competitive and rapidly changing environment.

The fact that employees and leaders in an organization are involved in idea generation and implementation makes the incorporation of the concept of organizational structure in this study very important. Organizational structure (organic and mechanistic) is comprised of leadership styles (transactional and transformational) and relationship style (between the organization and supervisors; the organization and employees; the supervisors and the employees; and among the employees). The interplay of the leadership and relationship styles can positively or negatively impact the employees' innovativeness. Haven recognized the importance of innovation or knowledge creation in organizations; scholars have tried to find out the exact mechanism for it. Among all, Nonaka and Takeuchi (1995) have developed a theory of organizational knowledge creation, which have gradually gained significance in the last decade. Nonaka and Takeuchi posit that knowledge creation is the result of the interaction and conversion between two kinds of knowledge, that is, tacit and explicit knowledge. There are four modes of conversion mechanisms in the process of knowledge creation: socialization (from tacit knowledge to tacit knowledge), externalization (from tacit knowledge to explicit knowledge), combination (from explicit knowledge to explicit knowledge), and internalization (from explicit knowledge to tacit knowledge). 
The conversion of tacit to explicit knowledge is a social process between individuals (Popadiuk and Choo, 2006; Vonkrogh, 1998). Based on a constructionist perspective (Vonkrogh, 1998), Nonaka and Takeuchi (1995) treated knowledge as "justified true belief" instead of what cognitivists called "representation" meaning that knowledge is universal. In this study, the view that individuals have to justify the truthfulness of their beliefs through personal sensemaking and individual experience under the interaction between themselves and the social context which they are embedded in is adopted (Vonkrogh, 1998; King and Zeithaml, 2003; Murray and Blackman, 2006). This implies that the innovativeness of individuals/employees in an organization is enhanced by the good relationship and leadership styles within the organization.

Though, Nonaka and Takeuchi (1995) theory of organizational knowledge creation gives us a clear picture of how knowledge is converted and socialized within organizational context. Nevertheless, some issues needs to be further investigated. Nonaka and Takeuchi did not categorize knowledge creation (innovation) process; the system/structure (if any) that facilitates the process was not mentioned; and the leadership and relationship styles that enhances employees' innovativeness were not identified. This study therefore seeks to examine the link among the organic and mechanistic structures, the innovation process, and leadership and relationship styles.

\subsection{Organizational Structure}

\section{Literature Review}

The organization structure is a framework of roles, responsibilities, authority and communication relationships that are deliberately designed to accomplish an organization's tasks and achieve its objectives. The organization structure is also called the organization chart/organogram (Ottih, 2008). Burns and Stalker (1961) were the first to indicate that different types of organizational structures might be effective in different situations. Furthermore, Burns and Stalker identified two extreme types of organizational structure. The mechanistic (mechanic) structure which is found in organizations operating under stable environmental conditions, and the organic (dynamic/bio) structure which is found or rather is best suited, to organizations operating under unstable environmental conditions. They also suggested eight characteristics or factors (task complexity, task definition, responsibility, control, expertness, communication, loyalty and prestige) of organizational form that vary between these two extreme forms of organizational structure.

Furthermore, Gold et al. (2001) argued that knowledge can be leveraged by means of organizational structure to facilitate the flow of organizational knowledge. This organizational knowledge is generated by knowledge workers via learning in knowledge-based or innovative organizations. It is generally accepted that leadership/managerial style supports innovation or knowledge management initiatives which in turn results in perceived benefits (Goh, 2003; Zammuto and O'Connor, 1992). Other scholars deem organizational structure as one of the forms of control (Blau and Scott, 1962; Lebas and Weigenstein, 1986) which aims to encourage organizational members to behave in a certain way towards organizational goals (Cardinal, 2001).

\subsection{Leadership Styles}

Knowledge is embodied in a person; generated by knowledge workers or employees; and made productive by the manager/leader of the organization (Drucker, 2001). Similarly, a wide range of factors have been found to affect organizational innovativeness in a competitive business environment. Of these factors, the managers' leadership style has been identified as the most influential factor (Jung et al., 2004). Therefore, to respond to the competitive business environment, adaptive leadership is considered to be an appropriate tool (Bass and Avolio, 1990). Adaptive leadership behaviour is termed transformational leadership and is known to affect innovation, especially organization's tendency to innovate (Gumusluoglu and Llsev, 2009). The organization's tendency to innovate implies idea generation in the innovation process.

Transformational leadership has five components: (1) idealized influence: refers to the leaders charismatic actions that focus on values, beliefs and sense of mission; (2) attributive charisma: is made up of leader's socialized charisma, that is, perception of the leader as being confident and powerful; (3) inspirational motivation: includes techniques leaders use to boost their followers by taking into view the optimistic future and determined goals; (4) intellectual stimulation: refers to challenging followers to practice creative thinking and finding solution to difficult problems; and (5) individualized consideration: includes the behaviour displayed by the leader that contributes to the satisfaction of the followers (Avolio et al., 1999). Transformational leaders help followers by arranging their values and norms; encouraging them to bring change in their personal as well as organizational life; and help them to perform beyond their expectation (House and Shamir, 1993; Jung and Avolio, 2000). Transformational leaders are: proactive; works to change the organizational culture by implementing new ideas; motivates and empowers employees to achieve company's objectives by appealing to higher ideas and moral values (Bass, 1985).

Conversely, transactional leaders overemphasize detailed and short-term goals, and standard rules and procedures. They do not make effort to enhance followers' ability to generate new ideas or better still, to be 
innovative. Transactional leaders are responsive; works within the organizational culture; makes employees achieve organizational objectives through rewards and punishment. They are quite effective in guiding efficient decisions which are aimed at cutting costs and improving productivity, and are highly directive and action oriented. A transactional leader has a predictable impact on innovation behaviour and performance (Feng et al., 2010). Transactional leadership, according to Bass (1985) is characterized by the following three factors: (1) contingent rewards, a leadership style which provides material and mental rewards according to the completion of promised obligations by subordinates, based upon specific role and task requirement; (2) active managementby-exception, which refers to a style of leadership whereby the leader carries out positive supervision of performance to avoid mistakes; and (3) passive management-by-exception, a style of leadership whereby the leader intervenes only after the appearance of behaviours or mistakes against the requirements.

\subsection{The Innovation Process}

The concept of innovation as cited by De Jung (2006) was first considered by Schumpeter (1943). According to De Jung, Schumpeter described it as innovation process - creation of new brand, products, services and processes, and its impact on economic development. It is an activity intended to develop an idea, carry it out, react to it and modify it where necessary (Van de ven, 1986). Innovation is the adoption of new approaches for an organization (Lee and $\mathrm{Yu}, 2010$ ). But there is a school of thought that does not emphasize the meaning of innovation; rather it concentrates on specifying different aspects and stages of the innovation process. An example of these is the definition of innovation by Thompson (1969) - innovation is the generation, acceptance and implementation of new ideas, processes, products and services. The innovation process according to Wilson (1966) is divided into three stages - idea conception, proposal, and adoption and implementation. But the current study is adopting it as four stages thus: idea generation, proposal, adoption and implementation.

The idea generation stage is where an idea regarding something new (product, production process, service, system, method, policy) is conceptualized by an individual or a group of persons in the organization. The second stage is the proposal stage; it is where an idea or concept is transformed into a proposal for official acceptance. The third stage is the adoption stage, it is where a proposed innovation is legitimated or becomes officially accepted. This is the stage where the decision for giving the innovation the attention needed in effort, time and money to be fully developed is made. The final stage is the implementation stage; it concerns the actual utilization of the innovation by organizational members as they perform their tasks. In the case of new products this might include the trial of new product before a commitment is made for its full establishment.

In spite of the fact that the importance of developing capabilities of idea/knowledge generation has been highlighted, the mechanisms that lead to and coordinate the innovation process remain much more to be investigated (Jansen et al., 2006). Prior research mostly focused on formal organizational structure and does not pay too much attention on the influence of informal social relations (like leadership and relationship styles) on the development of innovation (Rothaermel and Deeds, 2004; Subramaniam and Youndt, 2005; Jansen et al., 2006).

The context of organizational structure refers to the establishment of tangible administrative mechanisms while social relations, which is intangible in nature facilitates the coordination of organizational members. It is important to note therefore that this issues points to the concept of "ambidexterity". The term "ambidexterity" was initially used by Duncan (1976) to describe organization's need to develop "dual structures" to cope with the tension between alignment (similar to the idea generation stage of the innovation process) and adaptation (similar to the implementation stage of the innovation process). At first, organizational scholars treated this contradictory tension as a trade-off in the organization's development, but now more and more attention has shifted to paradoxical thinking (Gibson and Birkinshaw, 2004). That is, in the present context, turbulent and competitive environment. Organizations have no choice but to develop both capabilities at the same time and within the same organizational department. Consequently, this study follows Gibson and Birkinshaw notion of "contextual ambidexterity" that organizations are to and have to simultaneously develop alignment and adaptability under the same organizational context. Gibson and Birkinshaw noted that "contextual ambidexterity" is different from "structural ambidexterity" because organizational features are more than formal structure. Moreover, organizational ambidexterity would be best achieved not by establishing dual structure rather by arranging an organizational context which may encourage and enable organizational members to develop skills at coping with the tension between adjustment and adaptation by their own judgment.

\subsection{The Moderating Role of Relationship Style}

Organizations in effect are made up of the work and relationship style (between the organization and supervisors; the organization and the employees; supervisors and employees; and among the employees). Thus, the nature of this relationship and the task structure among the employees depicts the organization structure. However, according to Graen (1976) the extent to which an employee in an organization can voluntarily share his/her knowledge with colleagues or the organization depends on the employee's role in the work group and the nature of the relationship the employee has with fellow workers, the supervisor and the organization. Petrash 
(1996) further noted that employees have more willingness to work hard when they maintain a good relationship with their supervisor. In general, mutual trust, respect, loyalty and obligation are higher between members who have better relationships in an organization. Given a good relationship atmosphere, employees can share their knowledge and experiences with others in an organization. Thus, the organizational and customer capital of such company will be increased and a core value will be created within the company.

Knowledge sharing allows members of an organization to learn more. Above all, and more importantly, knowledge provides the organization with an efficient tool to maintain competitive advantage. Thus, with increasingly updated technology and information, the work of physical labour has been gradually replaced by new technology and machines, and knowledge has become an occupational prerequisite in the new knowledge economic era. Learning important knowledge and skills within the organization through the establishments of relationship among members is helpful not only in enforcing collaboration, but also in spacing up the accumulation of knowledge assets for the organization to improve its innovative performance (Lee and $\mathrm{Yu}, 2010)$. Drucker (2001) emphasized that knowledge is always embodied in a person, carried by a person, created, augumented or improved by a person; applied, taught and passed on by a person; and used or misused by a person. The shift to knowledge society therefore puts the person in the center. With respect to the organization, persons are therefore involved; these persons are made up of the manager/leader of the organization and the employees in the organization. The employees generate and implement the idea under the leadership of the manager/leader. This also implies that the employees and the managers make knowledge productive. The challenge of the management/leadership becomes which organizational structure should be adapted so as to foster the right relationship among employees and supervisors and by extension enhance employees' innovativeness.

\subsection{Research Conceptual Model}

The conceptual model in Fig. 1 relates the innovation process to leadership styles (transactional and transformational) and the forms of organizational structure as put forward by Burns and Stalker (1961). Fig. 1 further depicts the moderator variable, relationship style, and the extent to which it moderates the impact of the leadership styles on the innovation process. It can be observed from Fig. 1 that as the innovation process moves from the idea generation to the implementation stage, the organization structure becomes less organic and more mechanistic.

\subsection{Research Hypotheses}

$\mathbf{H}_{\text {O1: }}$ Organic structure has no significant impact on idea generation.

$\mathbf{H}_{\mathbf{O} 2}$ : Mechanistic structure has no significant impact on idea implementation.

$\mathbf{H}_{\mathbf{0 3}}$ : Transformational leadership has no significant impact on idea generation.

$\mathbf{H}_{\mathbf{O} 4}$ : Transactional leadership has no significant impact on idea implementation.

$\mathbf{H}_{\mathbf{O}}$ : Relationship style does not moderate the impact of transformational leadership on idea generation.

$\mathbf{H}_{\mathbf{0 6}}$ : Relationship style does not moderate the impact of transactional leadership on idea implementation.

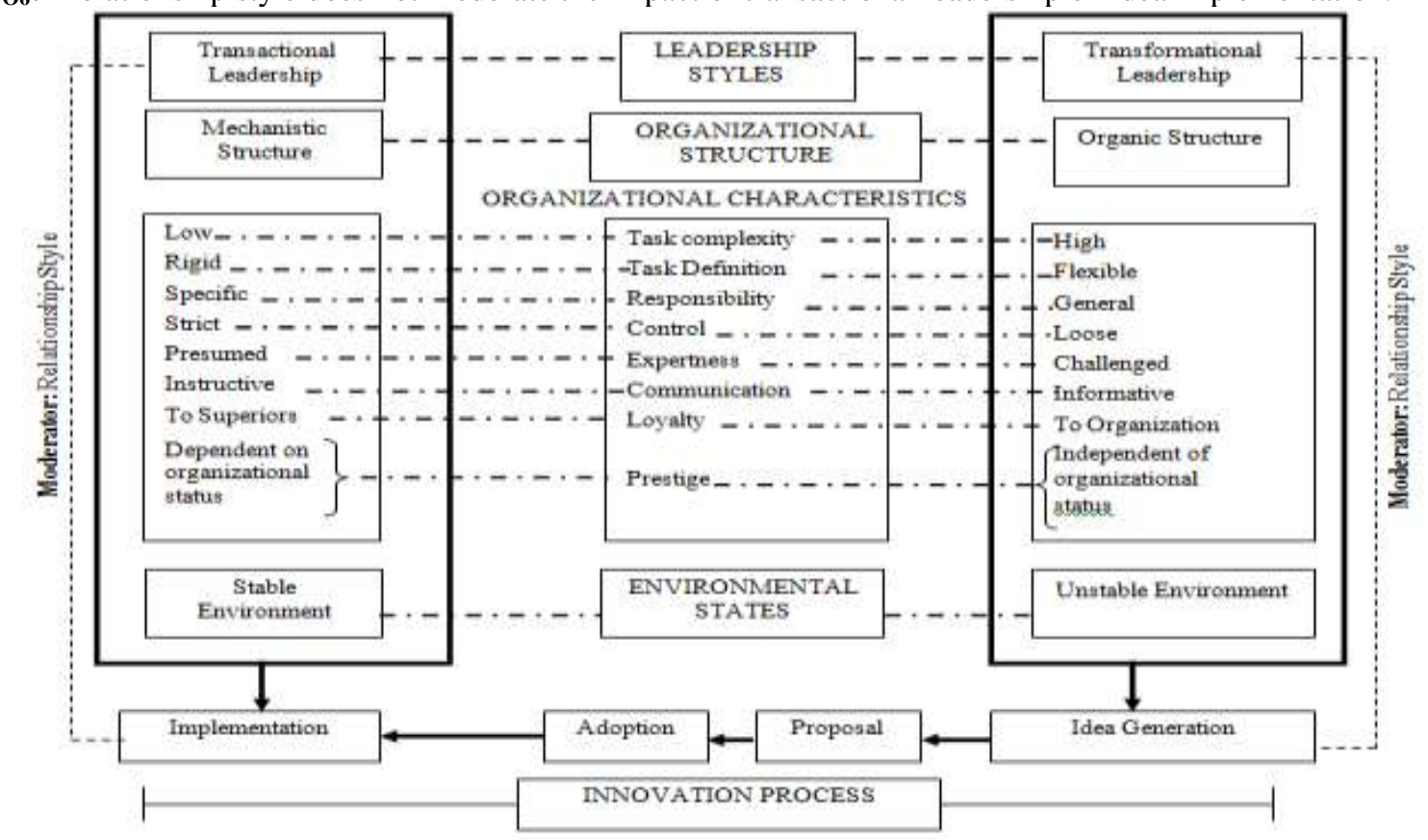

FIGURE 1: Conceptual Model 


\section{Methodology}

The field study was based on the survey of 43 manufacturing companies located in Anambra State, Nigeria. The companies were selected from the Anambra State industrial directories. Data for the study were collected by means of questionnaire. The questionnaire had five parts with 28 self developed items. Part one had eight items to measure organic structure, part two had eight items to measure mechanistic structure, part three had five items to measure transformational leadership, part four had three items to measure transactional leadership and part five had four items to measure relationship style. The questionnaire adopted a 5-point Likert scale whose degree of agreement ranged from strongly disagree (1) to strongly agree (5).

Out of the 664 questionnaires that were sent out, 38 were discarded on account of missing data, leaving 626 useable questionnaires for a response rate of $94.3 \%$. Regression analysis was employed to test the hypotheses at $95 \%$ confidence level, that is, at a p-value of less than or equal to 0.05 . Data analysis was done with the aid of SPSS (Version 18.0). The reliability of the constructs used in the study was done using internal consistency test. The Cronbach alpha coefficient of all the constructs surpassed the threshold of 0.70 suggested by Nunnally and Bernstein (1994). Among the companies studied, $92.2 \%$ had mechanistic structure, while 7.8\% had organic structure. Concerning leadership styles, $79.5 \%$ and $20.5 \%$ of them employed transactional and transformational leader styles respectively in the management of their companies.

\subsection{Results of the Tested Hypotheses}

$\mathbf{H}_{01}$ : Organize structure has no significant impact on idea generation.

Table 1 revealed the result of the $\mathrm{H}_{01}$ test with organic structure as independent variable and idea generation as the dependent variable. It is evident from table 1 that the beta value (0.358) is significant at $\mathrm{P}<0.05$. Thus, $\mathrm{H}_{01}$ is rejected, that is, organic structure impacts idea generation positively and significantly.

TABLE 1: Coefficients in the Regression Analysis of Organic Structure and Idea Generation

\begin{tabular}{llllll}
\hline Predictor variable & B & Std. Error & Beta & t & Sig. \\
\hline (Constant) & 81.642 & 1.846 & & 48.753 & 0.000 \\
Organic structure & 0.243 & 0.034 & 0.358 & 7.685 & 0.000 \\
\hline
\end{tabular}

$\mathbf{H}_{\mathbf{0 2}}$ : Mechanistic structure has no significant impact on idea implementation.

To test $\mathrm{H}_{02}$, mechanistic structure was chosen as the independent variable while idea implementation was the dependent variable. The result in Table 2 showed that the beta value of 0.382 is significant $(\mathrm{P}<0.05)$. Therefore, $\mathrm{H}_{02}$ is rejected. This implies that mechanistic structure impacts idea implementation positively and significantly.

TABLE 2: Coefficients in the Regression Analysis of Mechanistic Structure and Idea Implementation

\begin{tabular}{llllll}
\hline \multicolumn{1}{c}{ Predictor variable } & B & Std. Error & Beta & t & Sig. \\
\hline (Constant) & 84.346 & 1.765 & & 47.635 & 0.000 \\
Mechanistic structure & 0.196 & 0.035 & 0.382 & 6.852 & 0.000 \\
\hline
\end{tabular}

$\mathbf{H}_{03}$ : Transformational leadership has no significant impact on idea generation.

To test $\mathrm{H}_{03}$, a regression analysis was performed with idea generation and transformational leadership as the dependent and independent variables respectively. The result in Table 3 showed that the beta value $(0.284)$ is significant $(\mathrm{P}<0.05)$. Thus, $\mathrm{H}_{03}$ is rejected. Hence, transformational leadership has a positive and significant impact on idea generation.

TABLE 3: Coefficients in the Regression Analysis of Transformational Leadership and Idea Generation

\begin{tabular}{llllll}
\hline \multicolumn{1}{c}{ Predictor variable } & B & Std. Error & Beta & t & Sig. \\
\hline (Constant) & 49.357 & 1.352 & & 35.247 & 0.000 \\
Transformational leadership & 0.189 & 0.030 & 0.284 & 3.321 & 0.000 \\
\hline
\end{tabular}

$\mathbf{H}_{04}$ : Transactional leadership has no significant impact on idea implementation

A single variable regression was employed to test the impact of transactional leadership (independent variable) on idea implementation (dependent variable). The result in Table 4 revealed that the beta value $(0.276)$ is positive and significant $(\mathrm{P}<0.05)$. Thus, $\mathrm{H}_{04}$ is rejected. This implies that transactional leadership impacts idea implementation positively and significantly. 
TABLE 4: Coefficients in the Regression Analysis of Transactional Leadership and Idea Implementation

\begin{tabular}{llllll}
\hline Predictor variable & B & Std. Error & Beta & T & Sig. \\
\hline (Constant) & 44.226 & 1.241 & & 31.352 & 0.000 \\
Transactional & 0.143 & 0.033 & 0.276 & 3.024 & 0.000 \\
Leadership & & & & & \\
\hline
\end{tabular}

$\mathbf{H}_{05}$ : Relationship Styles does not moderate the Impact of Transformational Leadership on Idea Generation

Table 5 showed that the tested regression model is significant $(\mathrm{P}<0.05)$. The regression analysis accounted for $38 \%$ change in the relationship between transformational leadership and idea generation (dependent variable). The beta value revealed that the independent variable (transformational leadership) $(0.284)$ is significant $(\mathrm{P}<0.05)$. In addition, Table 6 showed that the linear regression model is significant $(\mathrm{P}<0.05)$. The regression analysis accounted for $46 \%$ change in the relationship as a result of the inclusion of the moderator variable, relationship styles. The beta value showed that the positive change between the independent variables $(0.604>0.568$, regression result from tables 6 and 5$)$ is significant $(\mathrm{P}<0.05)$. Thus, relationship style is a significant moderator since R-square value for transformational leadership * relationship style is greater than the R-square value for transformational leadership alone (36\% > 28\%, R-square values in Tables 6 and 5 respectively).

TABLE 5: Regression for the Moderating Impact of Relationship Style

\begin{tabular}{lllll}
\hline Model & R & R-Square & Adjusted R-square & Std. Error \\
\hline 1 & 0.568 & 0.380 & 0.286 & 0.4839 \\
& & Beta & $\mathrm{T}$ & Sig. \\
$\begin{array}{l}\text { Model } \\
\text { (Constant) }\end{array}$ & & & 35.247 & 0.000 \\
$\begin{array}{l}\text { Transformational } \\
\text { Leadership }\end{array}$ & & 0.284 & 3.321 & 0.000 \\
\hline
\end{tabular}

Predictor: (constant), transformational leadership

TABLE 6: Regression for the Moderating Impact of Relationship Style

\begin{tabular}{|c|c|c|c|c|}
\hline Model & $\mathbf{R}$ & R-Square & Adjusted R-square & Std. Error \\
\hline 1 & 0.604 & 0.462 & 0.308 & 0.5014 \\
\hline $\begin{array}{l}\text { Model } \\
\text { (Constant) }\end{array}$ & & Beta & $\begin{array}{l}\mathrm{t} \\
55.318\end{array}$ & $\begin{array}{l}\text { Sig. } \\
0.000\end{array}$ \\
\hline $\begin{array}{l}\text { Transformational Leadership* Relationship } \\
\text { Style }\end{array}$ & & 0.362 & 3.894 & 0.000 \\
\hline
\end{tabular}

Predictor: (constant), transformational leadership * relationship style

$\mathbf{H}_{06}$ : Relationship Style does not moderate the Impact of Transactional Leadership on Idea Implementation

Table 7 showed that the tested regression model is significant $(\mathrm{P}<0.05)$. The regression analysis accounted for $42 \%$ change in the relationship between transactional leadership and idea implementation (dependent variable). The beta value revealed that the independent variable (transactional leadership) (0.276) is significant $(\mathrm{P}<0.05)$. The regression analysis accounted for $47 \%$ change in the relationship as a result of the inclusion of the moderator variable, relationships style. The beta value showed that the positive change between the independent variables $(0.624>0.586$, regression result from Tables 8 and 7$)$ is significant $(\mathrm{P}<0.05)$. Thus, relationship styles are a significant moderator of the relationship between transactional leadership and idea implementation. This is owing to the fact that R-square value for transactional leadership * relationship style is greater than the R-square value for transactional leadership alone (47\% > 42\%, R-square values in Tables 8 and 7 respectively).

TABLE 7: Regression for the Moderating Impact of Relationship Style

\begin{tabular}{|c|c|c|c|c|}
\hline Model & $\mathbf{R}$ & R-Square & Adjusted R-square & Std. Errol \\
\hline 1 & 0.568 & 0.420 & 0.283 & 0.5234 \\
\hline $\begin{array}{l}\text { Model } \\
\text { (Constant) }\end{array}$ & & Beta & $\begin{array}{l}\mathrm{t} \\
31.352\end{array}$ & $\begin{array}{l}\text { Sig. } \\
0.000\end{array}$ \\
\hline Transactional Leadership & & 0.276 & 3.024 & 0.000 \\
\hline
\end{tabular}




\begin{tabular}{|c|c|c|c|c|c|}
\hline Model & & $\mathbf{R}$ & R-Square & Adjusted R-square & Std. Error \\
\hline 1 & & 0624 & 0.473 & 0.324 & 0.5364 \\
\hline $\begin{array}{l}\text { Model } \\
\text { (Constant) }\end{array}$ & & & Beta & $\begin{array}{l}\mathrm{t} \\
48.537\end{array}$ & $\begin{array}{l}\text { Sig. } \\
0.000\end{array}$ \\
\hline $\begin{array}{l}\text { Transactional } \\
\text { style }\end{array}$ & Leadership* Relationship & & 0.342 & 3.567 & 0.000 \\
\hline
\end{tabular}

\section{Conclusion}

This study conceptualized and empirically investigated the impact of the relationship among organizational structure, leadership styles (transactional and transformational), relationship style (between the organization and the supervisor; the organization and the employees; the supervisors and the employees; and among the employees) and the innovation process. The knowledge creation (or innovation) theory by Nonaka and Takeuchi (1995) served as the theoretical framework as it helped to establish the relationship among the constructs and to investigate the possibility of an organization assuming ambidextrous position at the same time in the same department. Consequently, the study found from the hypotheses tested that: organic structure has significant impact on idea generation; mechanistic structure impacts idea implementation positively and significantly; transformational and transactional leadership impacts idea generation and implementation respectively; and relationship style moderates the relationship between transformational leadership and idea generation, and between transactional leadership and idea implementation. This therefore connotes that an organization could be ambidextrous at the same time and within the same department. A manager that is aspiring to develop innovative employees and a competitive organization in a turbulent environment is thus advised to employ both structures and leadership styles with a good relationship atmosphere among supervisors and employees within the organization.

\section{References}

[1] A. K. Karami, An Inspection on environmental scanning and Growth Strategy in High Tech Small Firms, Conf. on Small Firms, University of Twente, the Netherlands, 2008.

[2] B. E. A. Oghojafor, D. Olamitunji, and A. A. Sulaimon, Assessing the small and medium scale enterprises environment in Nigeria. International Journal of African Studies, 4, 2001, 22-27.

[3] N. E. Akpotu, Education as correlate of fertility rate among families in southern Nigeria, Journal of Human Ecology, 23(1), 2008, 65-70.

[4] Oki, The global financial crisis and the Nigerian banking sector. Journal of Contemporary Issues in Development Finance and Entrepreneurship, 1(1), 2009, 8-13.

[5] I. Nonaka, and H. Takeuchi, The knowledge creating company (New York: Oxford University Press, 1995).

[6] S. Popadiuk, and C. W. Choo, Innovation and knowledge creation: how are these concepts related? International Journal of Information Management, 26, 2006, 302-312.

[7] G. Vonkrough, Care in knowledge creation. California Management Review, 40 (3), 1998, 133-153.

[8] A. W. King, and C.P. Zeithaml, Measuring organizational knowledge: a conceptual and methodological framework, Strategic Management Journal, 24, 2003, 763 -772.

[9] P. Murray, and D. Blackman, Managing innovation through social architecture, learning and competencies: a new conceptual approach. Knowledge and Process, Management, 13(3), 2006, 132 -143.

[10] L.O. Ottih, Organization theory: structure, design and process (Port Harcourt: Amex Publications, 2008).

[11] T. Burns, and G.M. Stalker, The management of innovation (London: Tavistock Publications,1961).

[12] A.H., Gold, A.H, Malhotra, and Segars, Knowledge management: an organizational capabilities perspective. Journal of Information Systems, 18 (1), 2001, 185-214.

[13] S.C. Goh, and G. Richard, Bench making the learning capabilities of the organizations. European Management Journal, 15(5), 1997, 575-583

[14] R.F. Zammuto, and E.J. O'connor, Gaining advanced manufacturing technology benefits: the roles of organization design and culture, Academy of Management Review, 17, 1992, 701-728.

[15] P, Blau, and R. Scott, Formal Organizations: A Comparative Approach (San Francisco: Chandler Publishing Company, 1962).

[16] M. Lebas, and J. Weigenstein, Management control: the role of rules, markets and culture, Journal of Management Studies, 23, 1986, 259-272.

[17] L.B. Cardinal, Technological innovation in the pharmaceutical industry: the use of organizational control in managing research development. Organization Science, 12(1), 2001, 19-36.

[18] P.F. Drucker, The essential drucker (New York: Harper Collins, 2001).

[19] D. Jung, C. Chow, and A. Wu, The role of transformational leadership in enhancing organizational innovation: hypothesis and some preliminary findings (San Diego: San Diego State University center for international business education and research publication, 2004)

[20] B.M. Bass, and B.J. Avolio, The implications of transformational and transactional leadership for individual, team and organizational development (Greenwich, C.T.: JAI, 1990).

[21] T. Gumusluoglu, and A. Llsev, Transformational leadership, creativity and organizational innovation. Journal of Business Research, 62, 2009, 461-473.

[22] B.J. Avolio, R.M. Bass, and D.I. Jung, Re-examining the components of transformational leadership and transactional leadership questionnaire, Journal of Occupational and Organizational Psychology, 72, 1999, 441-462. 
[23] R.J. House, and B. Shamir, Toward the integration of transformational, charismatic and visionary theories, In M.M. Chemers, and R. Ayman (Eds.), Leadership theory and research: perspectives and direction, (San Diego: Academic Press, 1993) 15-20.

[24] D.J Jung, and B. Avolio, Opening the black box: an empirical investigation of the mediating effects of trust and value congruence on transformational and transactional leadership. Journal of Organizational Behaviour, 21, 2000, 949-964.

[25] B.M. Bass, Leadership and performance beyond expectation (New York: Free Press, 1985).

[26] W. Feng, X. Yuan, and Y. Di, Effects of transactional leadership, psychological empowerment and empowerment climate on creative performance of subordinates: a cross-level study. Frontiers of Business Research in China, 4(1), 2010, 29-46.

[27] J.P.J. De Jung, Individual innovation: the connection between leadership and employees' innovative work behaviour, Proc. on E.M Business and policy Research in its Series Scale Research Reports Number R200604, 2006. Retrieved October 24, 2010 from http://www.entreprenuership -sme.eu/pdf-ez/R200604.pdf

[28] A.H. Van de ven, Central problems in the management of innovation. Management Science, 32, $1986,590-608$.

[29] H Lee, and C. Yu, Effect of relationship style on innovation performance. African Journal of Business Management, 4(9), 2010, $1703-1708$.

[30] V.A. Thompson, Bureaucracy and innovation (Alabama: University of Alabama Press, 1969).

[31] J.Q. Wilson, Innovation in organization: notes towards a theory, in J.D.Thompson (Ed.), Approaches to organizational design (Pittsburgh: University of Pittsburgh Press, 1966) 16-22.

[32] J.J.P. Jansen, A.J. Frans, V.D. Bosch, and H.W. Volberda, Exploratory innovation, exploitative innovation and performance: effects of organizational antecedents and environmental moderators, Management Science, 52(11), 2006, 1661-1674.

[33] R.T. Rothaermel, and D.L. Deeds, Exploration and exploitation alliances in biotechnology: a system of new product development. Strategic Management Journal, 25, 2004, 201-221.

[34] M. Subramaniam, and M.A. Youndt, The diffusions, design and social shaping of production management information systems in Europe. Information Technology and People. 13(1), 2005, 27-45.

[35] R.B. Duncan, The ambidextrous organization: designing dual structures for innovation. In R.H. Kilmann, L.R. Pondy, and V. Slevin, (Eds.), The management of organization, (New York: North-Holland, 1976) 40-51.

[36] C.B. Gibson, and J.Birkinshaw, The antecedents, consequences and moderating role of organizational ambidexterity. Academy of Management Journal, 47(2), 2004, 209-226.

[37] G.B. Graen, Role making process within complex organizations, in V .Dummette (Ed.), Hand book on Industrial and Organizational Psychology, (London: LEA, 1976) 23-31.

[38] G. Petrash, Dow's journal to a knowledge value management culture, European Management Journal, 14(4), 1996, 365-373.

[39] J.C. Nunnally, and I. H. Bernstein, Psychometric theory (New York: McGraw-Hill, 1994). 